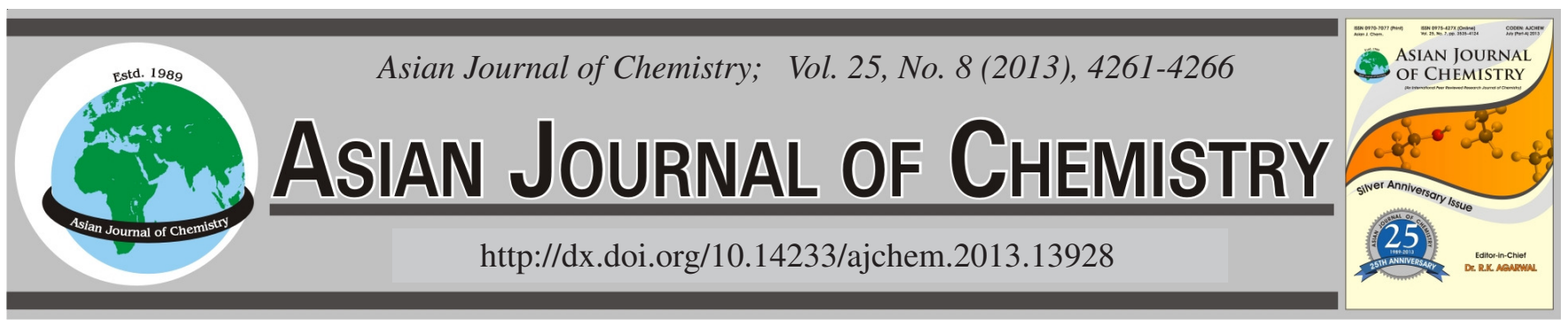

\title{
Isothermal and Thermodynamical Modeling of Removing Cationic Dyes Through Biosorption Using Simple and Chemically Modified Eugenia jambolana Seeds as Biosorbent
}

\author{
Rabia Rehman ${ }^{*}$, TARiQ Mahmud and WahEed-Uz-Zaman
}

Institute of Chemistry, University of the Punjab, Lahore-54590, Pakistan

*Corresponding author: Fax: +92 42 99230998; Tel: +92 42 99230463; Ext: 870; E-mail: grinorganic@ yahoo.com

\begin{abstract}
As biosorption is emerging as new waste water technique, the surge for new biosorbents is also increasing. Researchers are not only finding novel biosorbents, but they are also trying to modify them in order to enhance their biosorption capacity. In this study, the removal of methylene blue and brilliant green dyes from water had been studied using Eugenia jambolana seeds as biosorbent. Various factors which control the rate of biosorption process like biosorbent dose, $\mathrm{pH}$ of the dye solution, contact time interval, agitation rate and temperature are studied. Maximum biosorption capacity of chemically modified Eugenia jambolana seeds was 32.34 and $40.14 \mathrm{mg} / \mathrm{g}$ for methylene blue and Brilliant green dyes, respectively. Heats of biosorption were 6.5 and $9.21 \mathrm{~kJ} / \mathrm{mol}$ for methylene blue and brilliant green dyes, respectively. Chemical modification of these seeds was made with tartaric acid in order to enhance their biosorption capacity. Desorption and thermodynamical parameters were also investigated. The results revealed that Eugenia jambolana seeds can be an effective biosorbent for removing dyes from waste water.
\end{abstract}

Key Words: Methylene blue, Brilliant green, Eugenia jambolana seeds, Dyes, Biosorption.

\section{INTRODUCTION}

Now-a-days removal of toxic substances from waste water is a hot issue for environmentalists and chemists. They are finding new methodologies for effective removal of contaminants from waste water. Biosorption is becoming popular among researchers for water treatment, because it employs low-cost biosorbents of waste origin to sequester toxic substances. It is better than conventional methodologies because of reusability of biomaterials and low operational cost. Biomaterials remove dyes and metal ions from the effluent to a solid phase, resulting in minimal effluent volume. The used biosorbents can be regenerated and recycled or stacked away in a dry place without coming into direct contact with the environment. Different researchers exploit the biosorption capacity of various agricultural waste materials as biosorbent like rice husk, wheat husk, orange peels, coconut husk and shell, bagasse ash, banana peel, sea weeds, hazelnut shell, peanut hull, wheat bran, black gram husk, maize leaf, maize, sun flower waste, coffee beans, leaves of Polyalthia longifolia, Syzygium cumini and Ficus religiosa, almond shell and tea waste $^{1-14}$.

The present work seeks the feasibility of the use of Eugenia jambolana (Jamun) seeds as an alternate, low-cost, green biosorbent for removing methylene blue and brilliant green dyes from water. Eugenia jambolana (other name: Syzygium cumini) is the member of Myrtaceae family. Though its leaves have been used for lead and cadmium biosorption ${ }^{15,16}$ there is no information about its seeds biosorption potential towards cationic dyes like methylene blue and brilliant green. Eugenia jambolana is a fairly fast growing species, living mostly more than 100 years and can reach heights of up to 30$35 \mathrm{~m}$. Its seeds and bark are used in herbal and Ayurvedic medicines for controlling blood pressure and gingivitis. Its dense foliage provides shade and is grown just for its ornamental value. Its wood due to strong nature and water resistant properties, used as construction material. In Asian countries, it is used as the main constituents in many traditional herbal medicines for the treatment of diabetes mellitus ${ }^{17,18}$.

Dyes used in textile industries are mostly organic in nature, which are generally non biodegradable in the ecosystems. Due to their complex molecular structures, their removal treatment is very complicated. Basically, the dye molecules in effluent undergo structural changes by consuming dissolved oxygen or other oxidants present in effluent causing an increase in mortality rate of aquatic life. The minute release of dyes in water reduces photosynthetic activities of phytoplankton due to abnormal coloration of surface water ${ }^{19,20}$.

Present study has been conducted to remove two important and widely used cationic dyes, i.e., methylene blue and brilliant 
green from waste water. These are usually employed for dying in textile industries. Chemical formula of methylene blue is $\mathrm{C}_{16} \mathrm{H}_{18} \mathrm{~N}_{3} \mathrm{SCl} \cdot 3 \mathrm{H}_{2} \mathrm{O}$ and its structural formula is shown in Fig. 1. Brilliant green is a hazardous triphenyl nitrogen-containing cationic dye. Its structural formula is given in Fig. 2. Other than textile, the dyes are frequently used in paper printing and manufacturing of green ink. Brilliant green is used as a staining constituent of bacteriological media, as an indicator and as a topical antiseptic. Their ingestion causes burning sensation in alimentary canal and sometimes in severe cases results in diarrhea, nausea, gastritis, abdominal and chest pain, severe headache, urinary tract infection and anemia. Their contact with eyes results in irritation that can lead to permanent injury to the eyes of animals and human beings by damaging eye lenses and optic nerves. They have also mutagenic effects on microorganisms. Their thermal decomposition results in hazardous products like carbon oxides, nitrogen oxides and sulfur oxides. Therefore, their removal from effluent is necessary ${ }^{21-24}$.<smiles>CN(C)c1ccc2nc3ccc(N(C)C)cc3[s+]c2c1</smiles>

Fig. 1. Structural formula of methylene blue dye<smiles>CCN(CC)c1ccc(C(=C2C=CC(=[N+](CC)CC)C=C2)c2ccccc2)cc1</smiles>

Fig. 2. Structural formula of brilliant green dye

\section{EXPERIMENTAL}

All chemicals were purchased from Merck and used as such without further purification. Methylene blue dye (FW: $320 \mathrm{~g} \mathrm{~mol}^{-1}$, class: thiazine, C.I. Classification Number: 52015), Brilliant green dye (C.I.: 42040, FW: $462.65 \mathrm{~g} \mathrm{~mol}^{-1}$ ), $\mathrm{HCl}$, $\mathrm{NaOH}$, ethanol, iso-propanol, formalin, acetone, urea, tartaric acid, citric acid were used. Balance ER-120A (AND), electric grinder (Kenwood), pH meter (HANNA pH 211with glass electrode), FT-IR spectrometer (Perkin Elmer BX Model), electron microscope (JEOL, JXA-81000), UV/VIS spectrophotometer (Labomed, Inc. Spectro UV-VIS double beam UVD = 3500) were used.

Preparation of standards and working solutions: Stock solutions of dyes were prepared by dissolving $1.0 \mathrm{~g}$ in 1000 $\mathrm{mL}$ water. Standards and sample solutions were prepared from this stock solution by further dilution as required. Double distilled water was used for the preparation of solutions and dilutions where ever required.

Preparation of biosorbent: The seeds of Eugenia jambolana were purchased from local market of Lahore
(Pakistan). They were washed and dried in sunlight for 3 to 5 days. Then, they were dried in oven at $70{ }^{\circ} \mathrm{C}$ for $2 \mathrm{~h}$ to remove moisture completely and then ground into fine powder. After that, the seed powder was sieved to separate 60 mesh (ASTM) particle size powder and larger size particles were grinded again. This powder was stored in air tight plastic bottles till further use.

Instrumental analysis: The biosorbent surface was characterized by recording its FT-IR spectra before and after biosorption using FT-IR spectrometer in the range of 4000$400 \mathrm{~cm}^{-1}$. For SEM studies, the biosorbent powder before and after biosorption of dye were analyzed by electron microscope after coating them with gold through a gold sputter (JEOL, JXA-8100). The SEM images were shown in Figs. 3-5.

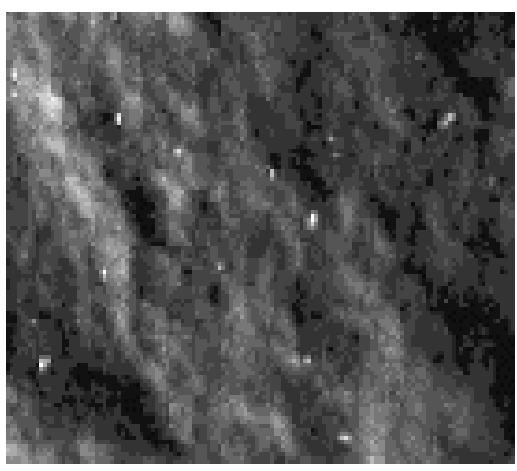

Fig. 3. SEM image of Eugenia jambolana seeds before biosorption

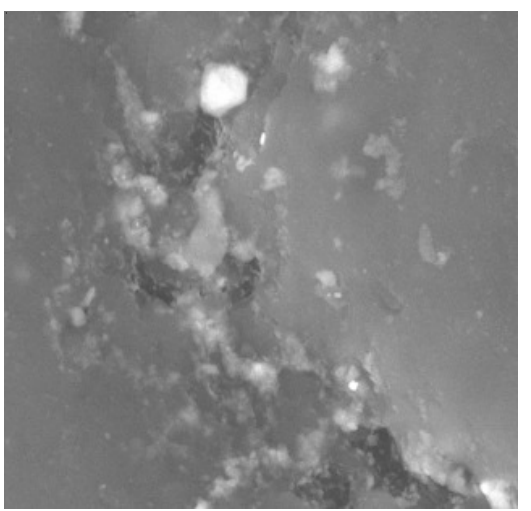

Fig. 4. SEM image of Eugenia jambolana seeds after biosorption of methylene blue dye

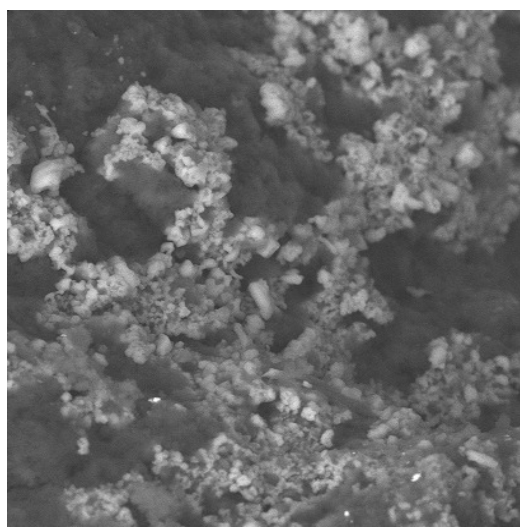

Fig. 5. SEM image of Eugenia jambolana seeds after biosorption of brilliant green dye 
Biosorption experiments for optimizing operational conditions: Biosorption experiments were performed at room temperature $\left(25 \pm 5^{\circ} \mathrm{C}\right)$ on orbital shaker at constant speed (100 rpm) using $100 \mathrm{~mL}$ conical flasks containing $25 \mathrm{~mL}$ of dye solution separately for methylene blue and brilliant green dye. Solution $\mathrm{pH}$ was adjusted to different values according to the requirement, with $0.1 \mathrm{~mol} \mathrm{~L}^{-1} \mathrm{HCl}$ and $0.1 \mathrm{~mol} \mathrm{~L}^{-1} \mathrm{NaOH}$. The effect of various parameters on the rate of biosorption process was investigated by varying the quantity of biosorbent (0.3-3.0 g), contact time, (5-50 min), $\mathrm{pH}$ of the solution (2-9), agitation speed (50-250 rpm) and temperature $\left(10-70{ }^{\circ} \mathrm{C}\right)$. After establishing equilibrium, the mixtures were filtered and the remaining dye was determined in the filtrate using UV/VIS spectrophotometer working at $662 \mathrm{~nm}$ for methylene blue and $625 \mathrm{~nm}$ for brilliant green dye. The percentage removal of dye at any instant of time was determined by the following equation $^{20}$ :

$$
\text { Removal of dye }(\%)=\frac{C_{o}-C_{e}}{C_{o}} \times 100
$$

Here, $C_{o}$ and $C_{e}$ are the concentrations of dyes before and after biosorption experiment, respectively. The results for optimizing of operational conditions of biosorbents are shown in Figs. 6-10.

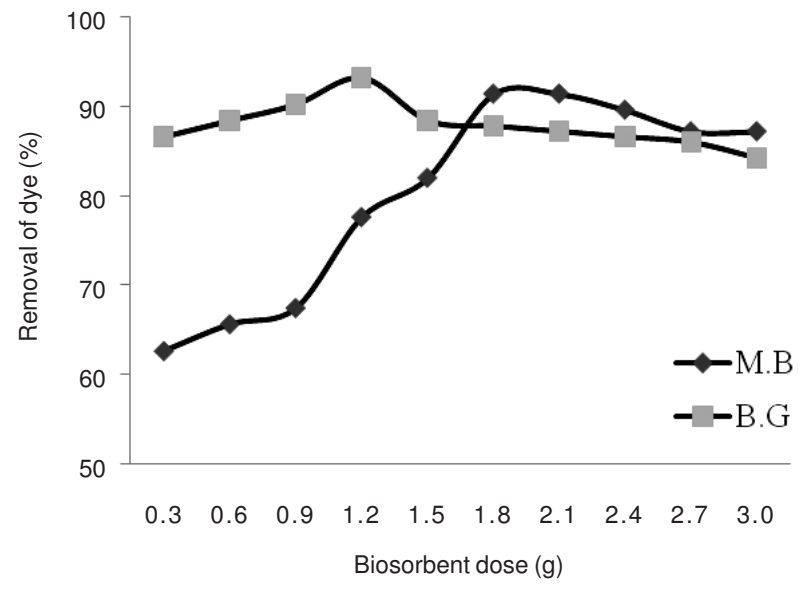

Fig. 6. Effect of biosorbent dose on percentage removal of dyes using Eugenia jambolana seeds. Where MB = methylene blue dye and $\mathrm{BG}=$ brilliant green dye

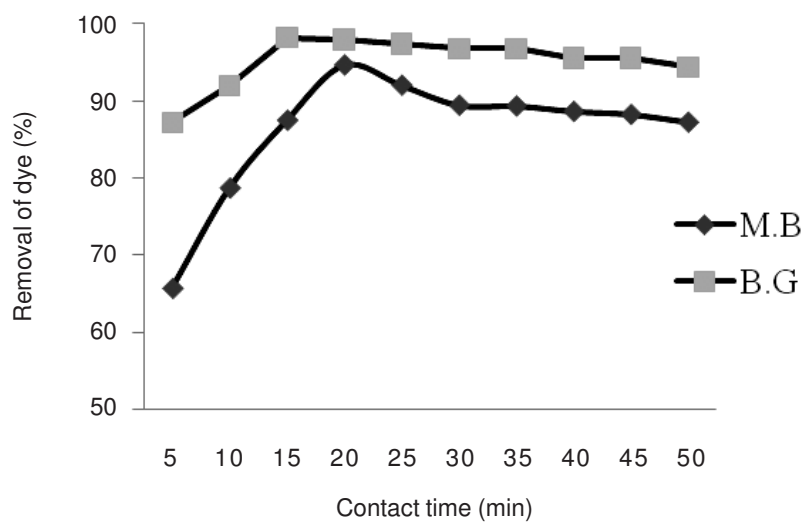

Fig. 7. Effect of contact time on percentage removal of dyes using Eugenia jambolana seeds. Where $\mathrm{MB}=$ Methylene blue dye and $\mathrm{BG}=$ brilliant green dye

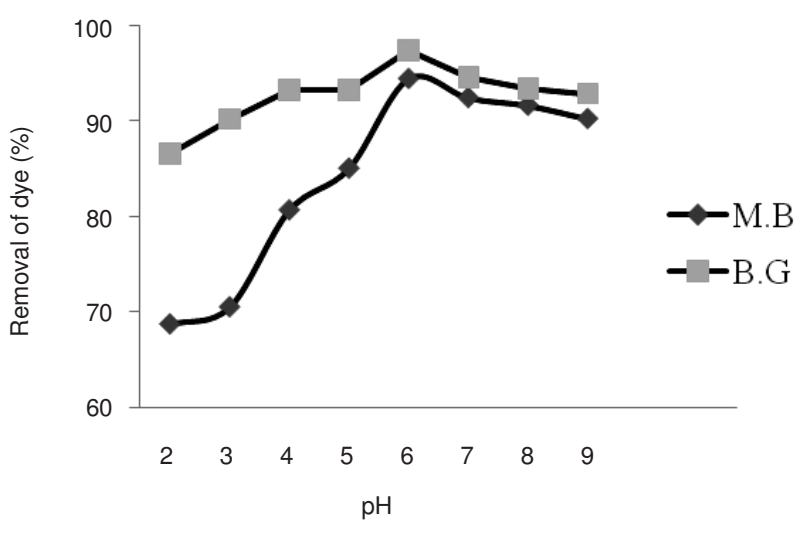

Fig. 8. Effect of $\mathrm{pH}$ on percentage removal of dyes using Eugenia jambolana seeds. Where $\mathrm{MB}=$ Methylene blue dye and $\mathrm{BG}=$ brilliant green dye

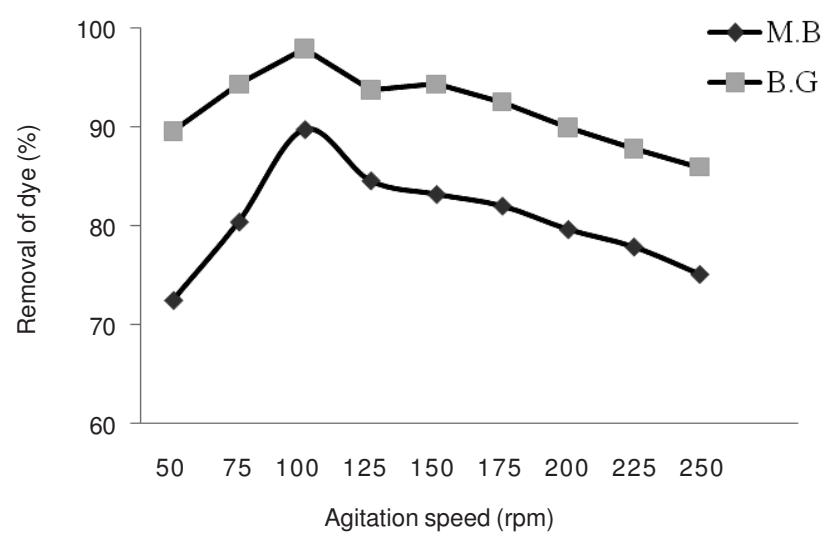

Fig. 9. Effect of agitation speed on percentage removal of dyes using Eugenia jambolana seeds. Where MB = Methylene blue dye and $\mathrm{BG}=$ brilliant green dye

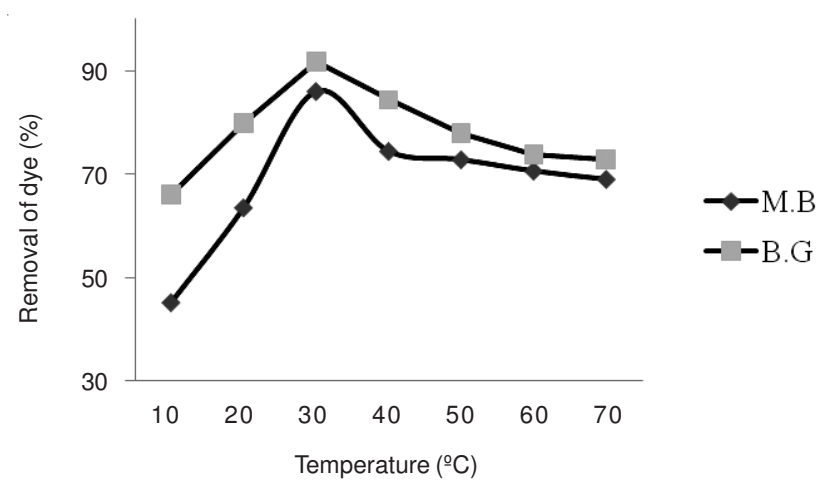

Fig. 10. Effect of temperature on percentage removal of dyes using Eugenia jambolana seeds. Where $\mathrm{MB}=$ Methylene blue dye and $\mathrm{BG}=$ brilliant green dye

Chemical modification of biosorbent: For evaluating the best modifying chemical reagent, Eugenia jambolana seeds were modified with different organic solvents like ethanol, iso-propanol, formalin and acetone and $15 \%$ aqueous solution of various chelating agents like urea, citric acid and tartaric acid were used for modification. $5.0 \mathrm{~g}$ of Eugenia jambolana seed powder was dipped in equal volumes of all these solutions separately in the beakers for $1 \mathrm{~h}$ after covering with aluminum foils. Then the contents were filtered and dried. Afterward, $1 \mathrm{~g}$ of modified biosorbent was dipped in $50 \mathrm{~mL}$ of $25 \mathrm{ppm}$ dye 
solution separately and agitated at $100 \mathrm{rpm}$ for $15 \mathrm{~min}$, followed by filtration of all the solutions $\mathrm{s}^{20,21}$. The remaining dye in all the filtrates was determined using UV/VIS spectrophotometer. Then the removal percentage of dye was calculated and plotted. The results are shown in Fig. 11.

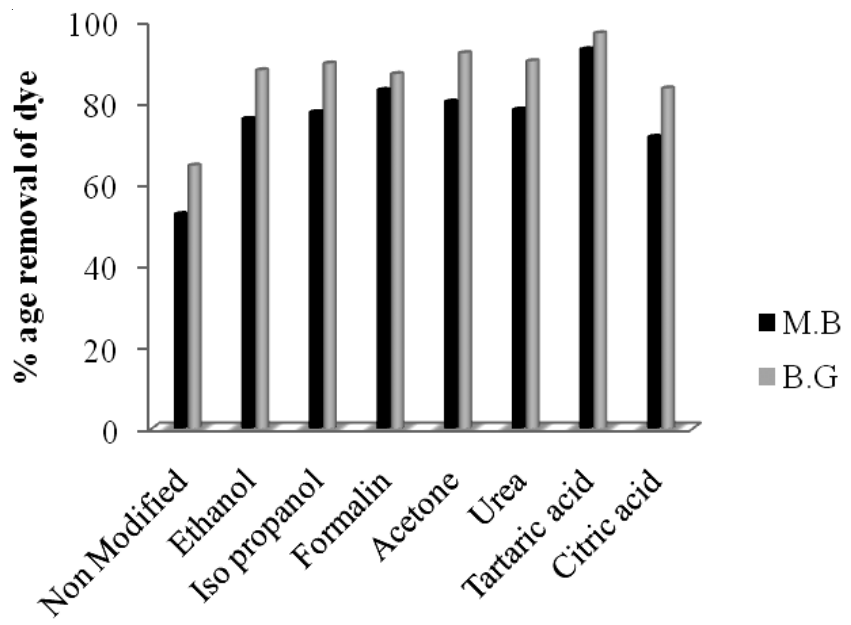

Chemicals Used

Fig. 11. Effect of chemical modification on adsorption capacity of Eugenia jambolana seeds on percentage removal of dyes from water. Where $\mathrm{MB}=$ Methylene blue dye and $\mathrm{BG}=$ brilliant green dye

Isothermal modeling: In modern engineering, before large scale investment, the behaviour of system is adequately modulated. Proper analysis and design of biosorption process require information regarding the relevant parameters. Isothermal studies were carried out for explaining biosorption equilibrium relationship at a given temperature using optimized conditions of all operating conditions of biosorption of dyes for finding the possible mechanism of removal of dyes. Langmuir model presumes the monolayer chemisorption phenomenon of biosorption of dye on biosorbent surface. Straight line equation for Langmuir isotherm was as followed:

$$
\frac{1}{\mathrm{q}}=\frac{1}{\mathrm{bq}_{\mathrm{m}} \mathrm{C}_{\mathrm{e}}}+\frac{1}{\mathrm{q}_{\mathrm{m}}}
$$

Here ' $\mathrm{q}^{\prime}\left(\mathrm{mg} \mathrm{g}^{-1}\right)$ is the amount of dye adsorbed, ' $\mathrm{C}_{\mathrm{e}}$ ' (ppm) is concentration of dye at equilibrium, ' $\mathrm{q}_{\mathrm{m}}$ ' $\left(\mathrm{mg} \mathrm{g}^{-1}\right)$ and b $\left(\mathrm{L} \mathrm{g}^{-1}\right)$ are Langmuir isotherm parameters which were calculated from the slope and intercept values of the regression plot variables. On the other hand, Freundlich model presumes the physiosorption phenomenon of biosorption on heterogeneous surface of biosorbent. Straight line equation for Freundlich isotherm was given below:

$$
\log \mathrm{q}=\log \mathrm{K}_{\mathrm{F}}+\frac{1}{\mathrm{n}} \log \mathrm{C}_{\mathrm{e}}
$$

' $\mathrm{K}_{\mathrm{F}}$ ' and ' $1 / \mathrm{n}$ ' are Freundlich isotherm parameters, which are calculated form regression analysis data. The Temkin isotherm model is based on the supposition that decrease in heat of sorption is the linear function of temperature and not logarithmic as in Freundlich model. The linear form of Temkin isotherm was:

$$
\mathrm{q}_{\mathrm{e}}=\mathrm{B}_{\mathrm{T}} \ln \mathrm{C}_{\mathrm{e}}+\mathrm{B}_{\mathrm{T}} \ln \mathrm{K}_{\mathrm{T}}
$$

Here $\mathrm{K}_{\mathrm{T}}$ is the equilibrium binding constant $(\mathrm{L} / \mathrm{mg})$ and $\mathrm{B}_{\mathrm{T}}$ is related to the heat of biosorption. The Temkin constants are obtained from the plot of $\mathrm{q}_{\mathrm{e}}$ versus $\ln \mathrm{C}_{\mathrm{e}}^{3,20-24}$.

Thermodynamical modeling: The fundamental criterion of spontaneity of adsorption process was Gibbs free energy change $\left(\Delta \mathrm{G}^{\mathrm{o}}\right)$. The process of adsorption occurs spontaneously at a given temperature if $\Delta \mathrm{G}^{\mathrm{o}}$ is a negative quantity. Its value was found by the equation:

$$
\Delta \mathrm{G}^{\mathrm{o}}=-\mathrm{RT} \ln \mathrm{K}
$$

where $\Delta \mathrm{G}^{\mathrm{o}}$ in $\mathrm{KJ} / \mathrm{mol}$, $\mathrm{T}$ is the absolute temperature in Kelvin, $\mathrm{R}$ is the universal gas constant with the value 8.314/1000 KJ $\mathrm{mol} /$ Kelvin and ' $\mathrm{K}$ ' is the reciprocal of Langmuir constant ' $\mathrm{b}$ '25.

Desorption studies: For finding a better eluent for desorption of dye from the biosorbent for its reusability, various acids were tried. The used seed powder of Eugenia jambolana was regenerated using $50 \mathrm{~mL}$ of $10.0 \mathrm{mmol} \mathrm{L}^{-1}$ solution of $\mathrm{HCl}, \mathrm{HNO}_{3}$ and $\mathrm{CH}_{3} \mathrm{COOH}$ separately in $250 \mathrm{~mL}$ conical flasks, while agitating at $100 \mathrm{rpm}$ for $20 \mathrm{~min}$ at room temperature. After that, regenerated biosorbents were dried in an oven at $80^{\circ} \mathrm{C}$ for $2-3 \mathrm{~h}$ and then reused. Desorption percentage was calculated using the equation ${ }^{22-24}$.

$$
\text { Desorption of dye }(\%)=\frac{\mathrm{q}_{\text {des }}}{\mathrm{q}} \times 100
$$

where $\mathrm{q}$ and $\mathrm{q}_{\mathrm{des}}$ are $\mathrm{mg} \mathrm{g}^{-1}$ of dye adsorbed and desorbed, respectively.

\section{RESULTS AND DISCUSSION}

Characterization of biosorbent: The surface of biosorbent was characterized by taking their FT-IR spectra and SEM images before and after biosorption of methylene blue and brilliant green dyes.

The vibrational frequencies of FT-IR spectra of Eugenia jambolana seeds before and after dyes biosorption are presented in Table-1. Broad and intense peaks at 3467, 3427 and $3421 \mathrm{~cm}^{-1}$ could be assigned to the stretching of O-H group due to inter- and intra molecular hydrogen bonding of alcohols, phenols and carboxylic acids which are normally present in pectin, cellulose and lignin. The bands at 2938, 2926 and 2918 $\mathrm{cm}^{-1}$ show $\mathrm{C}-\mathrm{H}$ stretching vibration of aliphatic acids. The bands at 2855,2847 and $2841 \mathrm{~cm}^{-1}$ are due to the symmetric stretching vibration of $\mathrm{CH}_{2}$ due to $\mathrm{C}-\mathrm{H}$ bonds of aliphatic acids. The bands observed at 1737, 1732 and $1728 \mathrm{~cm}^{-1}$ are because of the stretching vibration of $\mathrm{C}=\mathrm{O}$ bond due to nonionic carboxyl groups like - $\mathrm{COOH}$ or $-\mathrm{COOCH}_{3}$. Bands appearing at 1628, 1621, 1618, 1448, 1443, 1436, 1382, 1370 and $1368 \mathrm{~cm}^{-1}$ correspond to ionic carboxylic groups (-COO-) and aliphatic acid group, vibrations at 1256, 1246 and 1242 $\mathrm{cm}^{-1}$ were due to deformation vibration of $\mathrm{C}=\mathrm{O}$ and stretching formation of - $\mathrm{OH}$ of carboxylic acids and phenols. The bands at 1119,1112 and $1105 \mathrm{~cm}^{-1}$ were may be due to the presence of $>\mathrm{C}=\mathrm{S}$ group ${ }^{15}$.

It is well designated from FT-IR spectrum of Eugenia jambolana seeds that carboxyl and hydroxyl groups are present. These functional groups in biosorbents function as proton donors, so deprotonated hydroxyl and carboxyl groups were the possible binding sites for chelating dyes molecules during biosorption. 


\section{TABLE-1}

CHARACTERISTIC ABSORPTION FREQUENCIES OF

FT-IR SPECTRA OF Eugenia jambolana SEEDS BEFORE AND AFTER DYES BIOSORPTION

\begin{tabular}{ccc}
\multicolumn{3}{c}{ AND AFTER DYES BIOSORPTION } \\
\hline \multicolumn{3}{c}{ Vibrational frequencies $\left(\mathrm{cm}^{-1}\right)$} \\
\hline $\begin{array}{c}\text { Biosorbent before } \\
\text { biosorption }\end{array}$ & $\begin{array}{c}\text { Biosorbent after } \\
\text { biosorption of MB } \\
\text { dye* }\end{array}$ & $\begin{array}{c}\text { Biosorbent after } \\
\text { biosorption of BG } \\
\text { dye* }\end{array}$ \\
\hline 3446 & 3421 & 3427 \\
2938 & 2918 & 2926 \\
2855 & 2847 & 2841 \\
2740 & 2722 & 2731 \\
2157 & 2138 & 2142 \\
1737 & 1732 & 1728 \\
1628 & 1621 & 1618 \\
1448 & 1443 & 1436 \\
1382 & 1370 & 1368 \\
1256 & 1246 & 1242 \\
1161 & 1156 & 1149 \\
1119 & 1112 & 1105 \\
\hline *Where MB = Methylene blue dye and BG = Brilliant green dye.
\end{tabular}

On comparing the vibrational frequencies of Eugenia jambolana seeds before and after biosorption of dyes in Table-1, it is observed that after biosorption the bands had been shifted to lower wave numbers. These shifts were usually attributed to the fluctuations in counter ions association with carboxylate and hydroxylate anions. This suggests that the main coordinating groups in cationic dyes uptake may be acidic, carboxyl and hydroxyl groups ${ }^{18}$.

SEM images for Eugenia jambolana seeds before and after dye biosorption are shown in Figs. 3-5. When the texture of biosorbent loaded with dyes is compared with the unloaded one, it is observed that the biosorbent particles were agglomerated and produced distinct grains after methylene blue and brilliant green dye biosorption.

Biosorption studies: Various operational conditions of biosorption process were optimized. Biosorbent dosage is a crucial factor which controls the efficiency of biosorption process for removing contaminants from water. The study of biosorbent dose for removing methylene blue and brilliant green dyes from aqueous solution were carried out using Eugenia jambolana seed powder quantities ranging from 0.3 to $3.0 \mathrm{~g}$. The maximum percentage removal of dye was attained when biosorbent dose was $1.8 \mathrm{~g}$ in case of methylene blue dye and $1.2 \mathrm{~g}$ for brilliant green dye as clear from Fig. 6. The removal percentage of dye become constant for biosorbent quantities higher than these values. From these results, it is clear that seeds of Eugenia jambolana have adequate biosorption capacity.

The biosorbents with greater biosorption capacity usually remove impurities from water more efficiently in relatively less contact time intervals. The effect of various contact time between Eugenia jambolana seed powder with dye solution on percentage removal of methylene blue and brilliant green dye was studied. The results are shown in Fig. 7. The maximum removal of dye was obtained when the contact time was 20 min for methylene blue and $15 \mathrm{~min}$ for brilliant green dye. The maximum percentage removal of dye was 94.64 and 98.21 $\%$ for methylene blue and brilliant green dyes, respectively. The removal percentage of dye decreased to a constant value after equilibrium because all available binding sites were covered with dye molecules and no further active sites were available for further binding of dye molecules to biosorbent surface.

The effect of $\mathrm{pH}$ of the dye solution on removal of percentage dye form aqueous medium is shown in Fig. 8. The maximum removal percentage of cationic dyes was observed at pH 6 using Eugenia jambolana seeds.

The maximum removal percentage of methylene blue dye was $94.42 \%$, whereas it is $97.36 \%$ for brilliant green dye. At lower $\mathrm{pH}$, the biosorbent surface might have become negatively charged attracting more of the cationic dye molecules. In acidic solutions, the molecular form of the dye is the predominant adsorbed species, while in basic conditions; the ionized form is preferentially adsorbed. Biosorbent of agrowaste type origin contain a number of hydroxyl and carboxylate functional groups as chelating sites ${ }^{5-11}$.

The effect of variation in the agitation rate of dyes solution was studied in the range of 50-250 rpm and the results are given in Fig. 9. The maximum removal percentage of dyes was obtained when the agitation speed was $100 \mathrm{rpm}$. By increasing the agitation speed further, there was no increase in biosorption rate. It was observed that biosorption yield increased with decrease in agitation rate. The maximum removal percentage of methylene blue dye was $89.82 \%$ and for brilliant green dye, it was $97.98 \%$. The rate of agitation results in decreased boundary layer resistance between adsorbate and biosorbent, which enhances the mobility of biosorption system.

Temperature is a crucial factor in biosorption processes. The effect of this factor was determined and results are shown in Fig. 10. The maximum removal percentage of dyes occurred at $30^{\circ} \mathrm{C}$. Biosorption is usually an exothermic process, so an increase in temperature results in decreased biosorption capacity of Eugenia jambolana seeds. A long time exposure to high temperature can start decaying of biosorbent.

Isothermal modeling: The isotherm constants obtained for Langmuir, Freundlich and Temkin isotherms and the values of correlation coefficients $\left(\mathrm{R}^{2}\right)$ are given in Table-2. From this table, it is clear that Langmuir model holds good to explain biosorption of methylene blue and brilliant green dye on Eugenia jambolana seeds.

The correlation coefficient value $\left(\mathrm{R}^{2}\right)$ of Langmuir model values 0.989 and 0.986 implied a good mathematical fit for both methylene blue and brilliant green dyes. The data fitted indicated the homogeneous distribution of active sites on Eugenia jambolana seeds' surface which are responsible for chemisorption. These binding sites have the equivalent affinity for biosorption of a single molecular layer and there is no side interaction between adsorbed molecular species. This results in chemisorption. ' $\mathrm{q}_{\mathrm{m}}$ ' value was 32.34 and $40.14 \mathrm{mg} \mathrm{g}^{-1}$ methylene blue and brilliant green dyes, respectively.

The Freundlich isotherm model is an exponential equation which assumes that increase in concentration of adsorbate on biosorbent surface will occur with increasing concentration of adsorbate in solution ${ }^{20,25}$. It applies to biosorption on heterogeneous surfaces with interaction between adsorbed molecules and the adsorbent explains the physiosorption of 
TABLE-2

ISOTHERMAL AND THERMODYNAMICAL PARAMETERS FOR BIOSORPTION OF DYES ON Eugenia jambolana SEEDS

\begin{tabular}{|c|c|c|c|c|c|c|c|c|c|c|}
\hline \multirow{2}{*}{ Dyes } & \multicolumn{3}{|c|}{ Langmuir Isotherm Parameters } & \multicolumn{3}{|c|}{ Freundlich isotherm parameters } & \multicolumn{3}{|c|}{ Temkin isotherm parameters } & \multirow{2}{*}{$\begin{array}{c}\Delta \mathrm{G}^{\mathrm{o}} \\
(\mathrm{KJ} / \mathrm{mol})\end{array}$} \\
\hline & $\mathrm{R}^{2}$ & $\mathrm{q}_{\mathrm{m}}\left(\mathrm{mg} \mathrm{g}^{-1}\right)$ & $\mathrm{b}\left(\mathrm{L} \mathrm{g}^{-1}\right)$ & $\mathrm{R}^{2}$ & $\mathrm{~K}_{\mathrm{F}}$ & $1 / \mathrm{n}$ & $\mathrm{R}^{2}$ & $\mathrm{~K}_{\mathrm{T}}(\mathrm{L} / \mathrm{mg})$ & $\mathrm{B}_{\mathrm{T}}(\mathrm{kJ} / \mathrm{mol})$ & \\
\hline Methylene blue & 0.989 & 32.34 & 0.019 & 0.986 & 1.10 & 1.45 & 0.987 & 0.20 & 6.5 & -9.82 \\
\hline Brilliant green & 0.986 & 40.14 & 0.078 & 0.979 & 7.85 & 2.69 & 0.985 & 0.69 & 9.21 & -6.32 \\
\hline
\end{tabular}

adsorbate on biosorbent surface. The binding constant ' $\mathrm{K}_{\mathrm{F}}$ ' is always related to adsorption capacity ${ }^{25}$. Its values were 1.10 and 7.85 for methylene blue and brilliant green dyes, respectively. An empirical parameter related to adsorption intensity was ' $1 / \mathrm{n}$ ' whose value varies with the heterogeneity of the biosorbent surface. Its values were 1.45 and 2.69 for methylene blue and brilliant green dyes, respectively.

The Temkin constant ' $\mathrm{B}_{\mathrm{T}}$ ' is used to calculate heat of biosorption process. Its values were 6.5 and 9.21 for methylene blue and brilliant green dyes, respectively. $\mathrm{B}_{\mathrm{T}}$ values less than 8 indicate weak interaction between methylene blue and Eugenia jambolana seeds. But in case of brilliant green dye fairly strong chemical interaction takes place between dye and biosorbent, which are not easily reversible ${ }^{3,15}$.

Thermodynamical modeling: The Gibbs free energy of biosorption $\left(\Delta \mathrm{G}^{\mathrm{o}}\right)$ of methylene blue and brilliant green dyes on Eugenia jambolana seeds was calculated from the Langmuir model parameter ' $b^{125}$. It was -9.82 and $-6.32 \mathrm{KJ} /$ mol for methylene blue and brilliant green dyes, respectively. The negative value of $\Delta \mathrm{G}^{\mathrm{o}}$ confirmed the spontaneity and feasibility of biosorption process with greater removal of cationic dyes with Eugenia jambolana seeds.

Effect of chemical modification: The effective chemical for modification of Eugenia jambolana seeds has been revealed by Fig. 11. From this figure, it is clear that tartaric acid have modified Eugenia jambolana seeds powder significantly. It showed more biosorption capacity as compared to other chemically modified Eugenia jambolana seeds powder. It can remove $93.2 \%$ methylene blue and $97.3 \%$ brilliant green dye from water. Whereas non modified Eugenia jambolana seeds powder can remove 52.66 and $64.63 \%$ methylene blue and brilliant green dyes, respectively.

Basically all the agrowaste materials are cellulosic in nature. Tartaric acid enhances the removing capacity of biosorbent by chemically modifying cellulosic molecules of biosorbent. That is why further biosorption experiments for optimizing operational conditions were carried out by tartaric acid modified Eugenia jambolana seeds powder.

Desorption studies: The regeneration of used Eugenia jambolana seeds using different acids was quantified and results were shown in Fig. 12. It shows that dilute $\mathrm{HCl}$ is a good eluent for desorption of cationic dyes from Eugenia jambolana seeds.

\section{Conclusion}

From present studies, it can be safely concluded that Eugenia jambolana seeds is a good biosorbent for the removal of methylene blue and brilliant green dyes from waste water. Its efficiency can be further enhanced by chemically modifying it with tartaric acid. At pH 6 and $30^{\circ} \mathrm{C}$, the maximum biosorption capacity of Eugenia jambolana seeds for methylene blue and brilliant green dyes were found 32.34 and $40.14 \mathrm{mg}$ $\mathrm{g}^{-1}$, respectively.

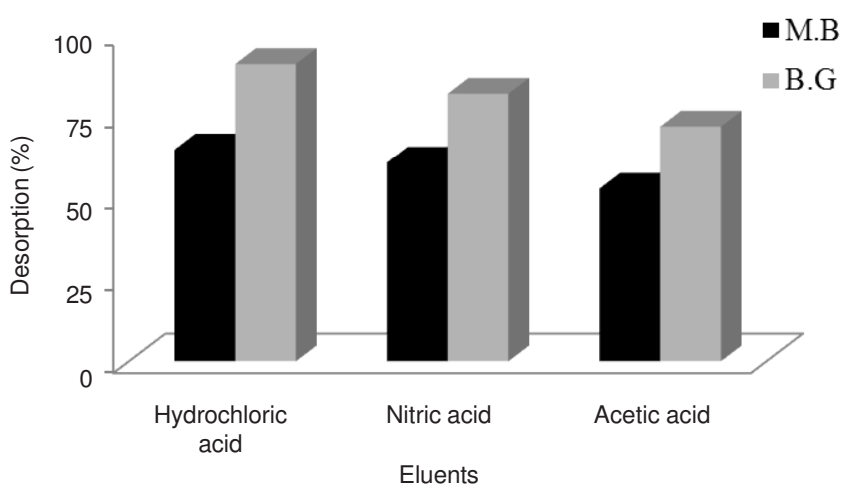

Fig. 12. Regeneration of Eugenia jambolana seeds using different eluents. Where $\mathrm{MB}=$ methylene blue dye and $\mathrm{BG}=$ brilliant green dye

\section{REFERENCES}

1. N. Ahalya, R.D. Kanamadi and T.V. Ramachandra, Electron. J. Biotechnol., 8, 258 (2005).

2. H. Gao, Y.G. Liu, G.M. Zeng, W.H. Xu, T. Li and W.B. Xia, J. Hazard. Mater., 150, 446 (2007).

3. J. Anwar, U. Shafique, W. Zaman, M. Salman, Z. Hussain, M. Saleem, N. Shahid, S. Mahboob, S. Ghafoor, M. Akram, R. Rehman and N. Jamil, Green Chem. Lett. Rev., 3, 239 (2010).

4. J. Wang and C. Chen, Adv. Biol. Technol., 27, 195 (2009).

5. J.L. Gardea-Torresdey, G. De La Rosa and J.R. Peralta-Videa, Pure Appl. Chem., 76, 801 (2004).

6. U. Farooq, J.A. Kozinski, M.A. Khan and M. Athar, Bioresour. Technol., 101, 5043 (2010).

7. M.R. Sangi, A. Shahmoradi, J. Zolgharnein, G.H. Azimi and M. Ghorbandoost, J. Hazard. Mater., 155, 513 (2008).

8. K.G. Bhattacharyya, J. Sarma and A. Sarma, J. Hazard. Mater., 165, 271 (2009).

9. A. Demirbas, J. Hazard. Mater., 157, 220 (2008).

10. G. Sun and W. Shi, Ind. Eng. Chem. Res., 37, 1324 (1998).

11. V. Sarin and K.K. Pant, Bioresour. Technol., 97, 15 (2006)

12. C. Raji and T.S. Anirudhan, Indian J. Chem. Technol., 4, 228 (1997).

13. T. Karthikeyan, S. Rajgopal and R. Miranda, J. Hazard. Mater., 124, 192 (2005).

14. A. Singh and I.S. Singh, Food Chem., 40, 221 (1991).

15. K.S. Rao, S. Anand and P. Venkateswarlu, Korean J. Chem. Eng., 27, 1547 (2010).

16. P. King, N. Rakesh, S.B. Lahari, Y.P. Kumar and V.S.R.K. Parsad, Chem. Eng. J., 144, 181 (2008).

17. H. Sagrawat, A.S. Mann and M.D. Kharya, Pharmacogn. Mag., 2, 96 (2006).

18. S. Mutalik, M. Chetena , B. Sulochana, P.U. Devi and N. Udupa, Phytother. Res., 19, 409 (2004).

19. M. Rafatullah, O. Sulaiman, R. Hashim and A. Ahmad, J. Hazard. Mater., 177, 70 (2010).

20. R. Rehman, T. Mahmud, J. Anwar, M. Salman, U. Shafique, W. Zaman and F. Ali, J. Chem. Soc. Pak., 33, 228 (2011).

21. R. Han, L. Zhang, C. Song, M. Zhang, H. Zhu and L. Zhang, Carbohydr. Polym., 79, 1140 (2010).

22. A.S. Franca, L.S. Oliveira and M.E. Ferreira, Desalination, 249, 267 (2009).

23. S.B. Bukallah, M.A. Rauf and S.S. AlAli, Dyes Pigm., 74, 85 (2007).

24. B.K. Nandi, A. Goswami and M.K. Purkait, J. Hazard. Mater., 161, 387 (2009).

25. N.A. Oladoja, C.O. Aboluwoye and Y.B. Oladimeji, Turk. J. Eng. Environ. Sci., 32, 303 (2008). 